\title{
SOME REMARKS ON THE COMPUTATION VIA SAMCEF AND THE SEMI-MOMENT THEORY FOR CYLINDRICAL SHELLS
}

\author{
NGo HuONg NhU, NGUYen Dang Hung \\ Institut of Mechanics Hanoi \\ LTAS Fracture Mechanics, University of Liege, Belgium
}

\section{Introduction}

In the paper [1] two solutions for cantilever cylindrical shells subjected to a bending moment $M$ and to concentrated force $F$ respectively on the free end of the shell are given. These results are based on semi-moment theory of cylindrical shell suggested by Vlasov.

In this work, cylindrical shell under above mentioned loads was calculated by SAMCEF [3]. The shell elements used in these case have all characteristics of moments and shear forces and therefore the results are more near to reality of stress state. The results received by FEM are compared with the analitical results in [1] and some remarks in this works are shown.

These remarks may be usefully for engineers and in researching theory of shell.

\section{On the semi-moment theory of cylindrical shells}

The basic assumptions of semi-moment theory Vlasov is summarized in the following: 1 . The bending moment of the shell along logitudinal direction is zero. 2 . The deformation in the cross direction is zero. Therefore torsion moment and also the cross force are neglected. It means that the bending here will be only in the cross direction of the tube. So there are following internal forces: axial forces and shear forces $N, T, S$, cross bending moment $M$ and cross force $Q$ (Fig. 1).

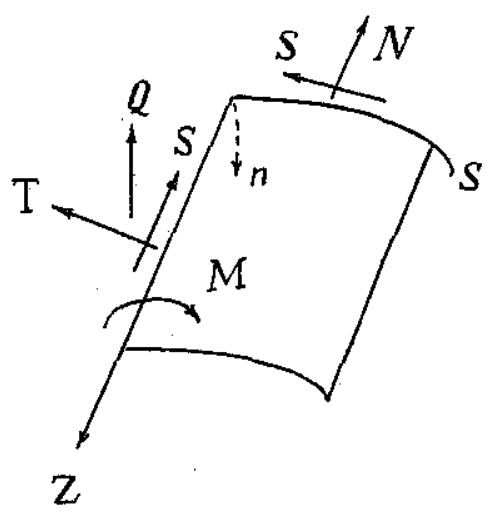

Fig. 1 
The equilibrium equations in this case has the form [2]:

$$
\begin{aligned}
& \frac{\partial N}{\partial z}+\frac{\partial S}{\partial s}+P_{z}=0 \\
& \frac{\partial S}{\partial z}+\frac{\partial T}{\partial s}-\frac{Q}{R}+P_{s}=0 \\
& \frac{\partial Q}{\partial z}+\frac{T}{R}+P_{n}=0 \\
& Q-\frac{\partial M}{\partial s}=0
\end{aligned}
$$

where, $R(s)$-the principal radius of curvature of the shell, $P_{z}, P_{s}, P_{n}$-components If external forces per unit area along direction of $z, s$ and $n$ respectively.

Eliminating from this system forces $S, T, Q$ one obtains the equation:

$$
\frac{\partial^{2}(\sigma h)}{\partial z^{2}}+\Omega M=P
$$

where $\Omega$ - Vlasov's operator:

$$
\begin{aligned}
& \Omega=\frac{\partial^{2}}{\partial s^{2}}\left(R \frac{\partial^{2}}{\partial s^{2}}\right)+\frac{\partial}{\partial s}\left(\frac{1}{R} \frac{\partial}{\partial s}\right) \text { and } \\
& P=\left[-\frac{\partial^{2}\left(P_{n} R\right)}{\partial s^{2}}+\frac{\partial P_{s}}{\partial s}-\frac{\partial P_{z}}{\partial z}\right]
\end{aligned}
$$

$\sigma=T / h \quad h$ - thickness of the shell.

The condition of compatibility of strains has the form:

$$
\frac{\partial^{2} k_{2}}{\partial z^{2}}+\frac{\partial^{2}}{\partial s^{2}}\left[R\left(\frac{\partial^{2} \varepsilon_{1}}{\partial s^{2}}+\frac{\partial^{2} \varepsilon_{2}}{\partial z^{2}}-\frac{\partial^{2} \omega}{\partial s \partial z}\right)\right]+\frac{\partial}{\partial s}\left[\frac{1}{R}\left(\frac{\partial \varepsilon_{1}}{\partial s}-\frac{\partial \omega}{\partial z}\right)\right]=0
$$

According to the assumption given by Vlasov $\omega=\varepsilon_{2}=0$, we have:

$$
\Omega \varepsilon_{1}+\frac{\partial^{2} k_{2}}{\partial z^{2}}=0
$$

Replacing here the strains by their expressions in terms of the forces and moment, and paying attention to the condition bending moments along longitudinal direction is zero. One has [1]:

$$
\Omega \sigma-\frac{E}{D\left(1-\nu^{2}\right)^{2}} \frac{\partial^{2} M}{\partial z^{2}}=0
$$


where $D$-the bending stiffness of the shell,

$$
D=\frac{E h^{3}}{12\left(1-\nu^{2}\right)}
$$

\section{The analy tical solutions for displacements and forces of cantilever cylindrical shell}

The equations (2.2) and (2.3) are two fundalmental equations of semi-moment Vlasov's theory. With some assumptions, the analytical solutions of this system are given in the paper [1] for two following cases:

3.1 Cantilever cylindrical shell $(R=$ constant $)$ subjected to a bending moment $M$ acting on the free end

In this case there are assumptions:

- The fundamental unknown $M$ and $\sigma$ are functions of $s$ only.

- The bending moment $M$ is expressed as linearly distributed normal stress with maximum value $\sigma_{0}$ that is the boundary condition has form (Fig. 4):

$$
\left.\sigma\right|_{z=\ell}=-\sigma_{0} \sin \theta
$$

As the results of solving equation (2.2) and (2.3) with above mention assumptions, the displacement components can be expressed as [1]:

$$
\begin{aligned}
u & =-\frac{\sigma_{0} h R^{2} z}{E h R^{2}-D \nu^{2}} \sin \theta \\
v & =-\frac{\sigma_{0}}{2} \frac{h R}{D \nu^{2}-E h R^{2}} z^{2} \cos \theta \\
w & =-\frac{\sigma_{0}}{2} \frac{h R}{D \nu^{2}-E h R^{2}} z^{2} \sin \theta
\end{aligned}
$$

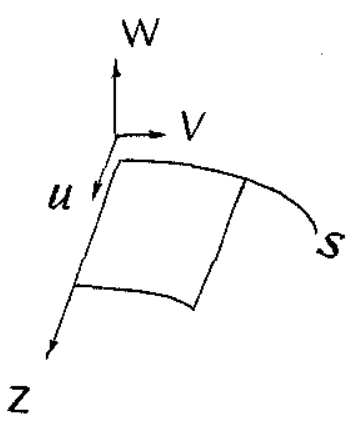

Fig. 2

and all internal forces have the forms:

$$
\begin{aligned}
N & =-\sigma_{0} h \sin \theta \\
S & =0
\end{aligned}
$$




$$
\begin{aligned}
T & =\frac{h D \nu \sigma_{0}}{E h R^{2}-D \nu^{2}} \sin \theta \\
Q & =\frac{h D \nu \sigma_{0}}{E h R^{2}-D \nu^{2}} \cos \theta \\
M & =\frac{h R D \nu \sigma_{0}}{E h R^{2}-D \nu^{2}} \sin \theta
\end{aligned}
$$

3.2 Cantilever cylindrical shell subjected to a concentrated force $F$ In this case there are assumptions:

- The fundamental unknown $M$ and $\sigma$ are functions of $s$ and $z$

- The solution of the problem has to satisfy equation (2.2) and (2.3) and boundary condition

$$
2 \int_{-\pi / 2}^{\pi / 2} S R \cos \theta d \theta=F \quad \text { at } z=\ell
$$

The maximum normal stress $\sigma_{0}$ acting on the fixed end is:

$$
\sigma_{0}=\frac{F \ell}{\pi R^{2} h}
$$

In this case the displacement components are received as:

$$
\begin{aligned}
u & =-\frac{\sigma_{0} h R^{2} z}{E h R^{2}-D \nu^{2}}\left(1-\frac{z}{2 \ell}\right) \sin \theta \\
v & =-\frac{\sigma_{0}}{2} \frac{h R}{D \nu^{2}-E h R^{2}} z^{2}\left(1-\frac{z}{3 \ell}\right) \cos \theta \\
w & =\frac{\sigma_{0}}{2} \frac{h R}{D \nu^{2}-E h R^{2}} z^{2}\left(\frac{z}{3 \ell}-1\right) \sin \theta
\end{aligned}
$$

The forces have the forms:

$$
\begin{aligned}
N & =\sigma_{0} h\left(1-\frac{z}{\ell}\right) \sin \theta \\
S & =-\frac{\sigma_{0} h R}{\ell} \cos \theta+\frac{1}{4 R}\left(F+\frac{R^{2} h \sigma_{0} \pi}{\ell}\right) \\
T & =\frac{h D \nu \sigma_{0}}{D \nu^{2}-E h R^{2}}\left(1-\frac{z}{\ell}\right) \sin \theta \\
Q & =\frac{h D \nu \sigma_{0}}{D \nu^{2}-E h R^{2}}\left(1-\frac{z}{\ell}\right) \cos \theta \\
M & =\frac{h R D \nu \sigma_{0}}{D \nu^{2}-E h R^{2}}\left(1-\frac{z}{\ell}\right) \sin \theta .
\end{aligned}
$$




\section{The numerical solutions given by SAMCEF for displace- ments and forces of cantilever cylindrical shell}

4.1 Cantilever cylindrical shell $(R=$ constant $)$ subjected to a bending moment $M$ acting on the free end

We consider cylindrical shell with:

$$
R=5 \mathrm{~m}, \ell=15 \mathrm{~m}, \quad h=0.05 \mathrm{~m} \text {, }
$$

$E=2.1 E 11 \mathrm{~N} / \mathrm{m}^{2}, \nu=0.3$.

The shell is cantilevered at $z=0$ and $z=\ell$, the moment $M$ is expressed as linearly distributed normal stress with maximum value $\sigma_{0}$. From boundary condition: $\left.\sigma\right|_{z=\ell}=-\sigma_{0} \sin \theta$

we can receive concentrated forces at discrete points respectively with angle $\theta$ at the boundary by this formula:

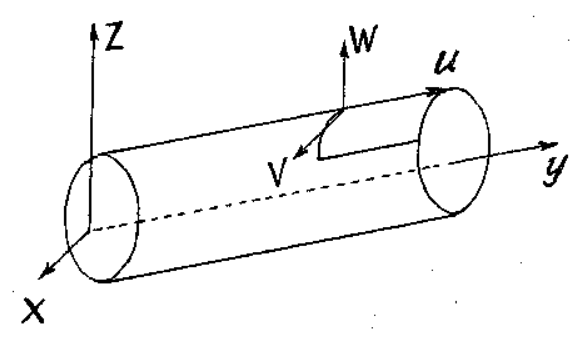

Fig. 3

$$
F_{y}=\frac{-2 \pi R h}{n} \sigma_{0} \sin \theta
$$

where $n$ is number of points at which there are concentrated loads.

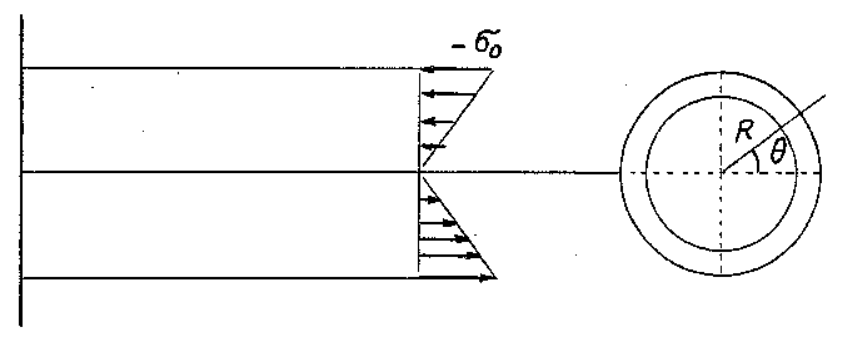

Fig. 4

Three cases of load distribution are considered in this work $(n=12, n=24$, $n=48$ ). In the quarters of section of cylinder, $F$ has these values respectively to different values $\theta$ :

- when $n=12: \quad F_{1}=-1 \cdot 10^{7} N, F_{2}=-0.86 \cdot 10^{7} N, F_{3}=-0.5 \cdot 10^{7} \mathrm{~N}$ $\left(\theta=90^{\circ}, 60^{\circ}, 30^{\circ}\right)$

- when $n=24: \quad F_{1}=-5 \cdot 10^{6} N, F_{2}=-4.8296 \cdot 10^{6} N, F_{3}=-4.3301$. $10^{6} \mathrm{~N}, F_{4}=-3.535 \cdot 10^{6} \mathrm{~N}, F_{5}=-2.5 \cdot 10^{6} \mathrm{~N}, F_{6}=-1.29410 \cdot 10^{6} \mathrm{~N},(\theta=$ $\left.90^{\circ}, 75^{\circ}, 60^{\circ}, \ldots\right)$

- when $n=48: F_{1}=-2.5 \cdot 10^{6} N, F_{2}=-2.4786 \cdot 10^{6} N, F_{3}=-2.4148 \cdot 10^{6} N$, 
$F_{4}=2.3079 \cdot 10^{6} \mathrm{~N}, F_{5}=-2.1651 \cdot 10^{6} \mathrm{~N}, F_{6}=-1.9834 \cdot 10^{6} \mathrm{~N}, F_{7}=-1.7678$. $10^{6} \mathrm{~N}, F_{8}=-1.5219 \cdot 10^{6} \mathrm{~N}, F_{9}=-1.25 \cdot 10^{6} \mathrm{~N}, F_{10}=-9.5671 \cdot 10^{5} \mathrm{~N}, F_{11}=$ $-6.4705 \cdot 10^{5} \mathrm{~N}, F_{12}=-3.2632 \cdot 10^{5} \mathrm{~N},\left(\theta=90^{\circ}, 82,5^{\circ}, 75^{\circ}, 67,5^{\circ}, \ldots\right)$.

The shell elements type 29 ,- based on the theory of Midlin [3], are used-in this work. The results of calculating by SAMCEF are given in table 1 and graphic 1,2 respectively to different mesh $(L, K)$ of the cylindrical shell, where $L$ and $K$ - the number of elements on the generatrix and on the circular line of cylinder. Figure 5 shows the picture of displacements of the cylinder in the case moment loading.

The numerical results given by SAMCEF are compared with the above described analytical results in the table 1, graphic 1,2 and Fig. 5. We can note that:

Nodal displacements ( $D X, D Y, D Z)$ Load casel

Poten. energy $0.3312 E 06$

Geometric scale

1.000

Numerical scale $1 / 2.592633$

Deformation scale: 170.37

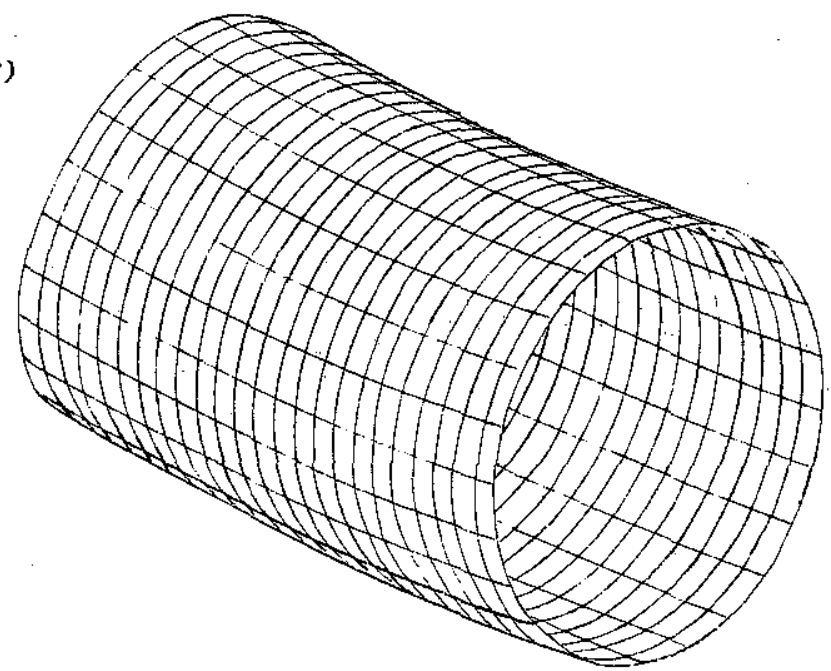

Fig. 5

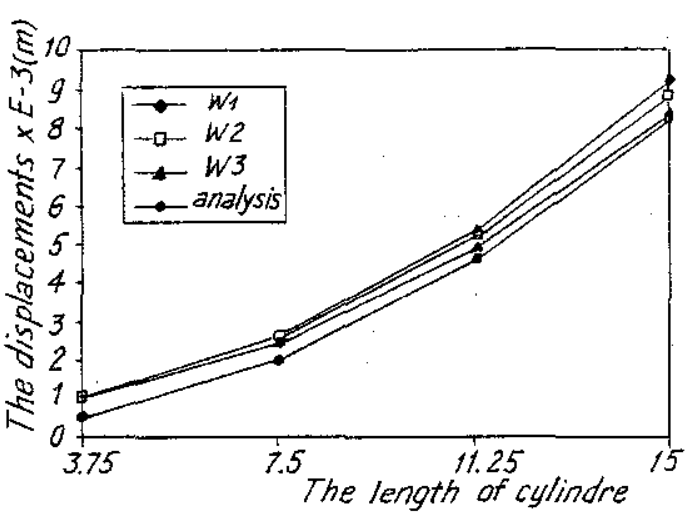

Graphic 1. The displacements $w$ for different meshes and analysis

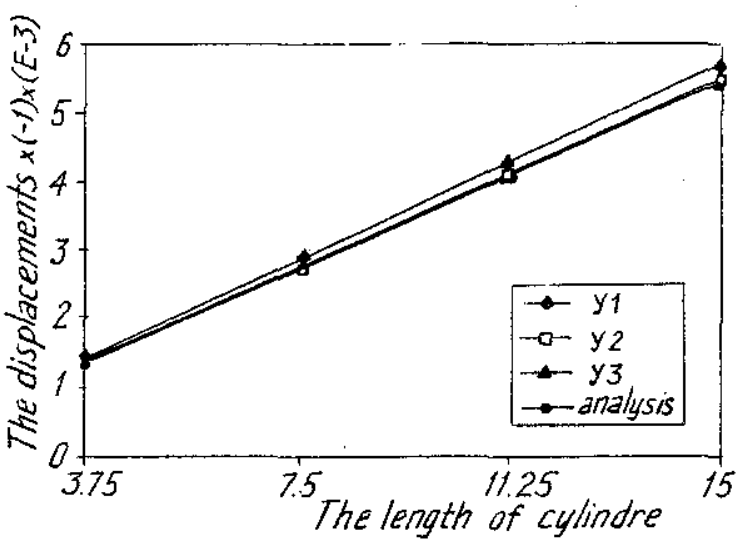

Graphic 2. The displacement along axis $y$ for different meshes and analysis 
THE DISPLACEMENTS (M) OF CYLINDER UNDER MOMENT LOADING, RECEIVED BY SAMCEF AND ANALYSIS

(For some nodes $x=0 \mathrm{~m}, z=5 \mathrm{~m}$ in the different sections $y$ )

Table 1

\begin{tabular}{|c|c|c|c|c|c|}
\hline \multirow[b]{2}{*}{ MDOF } & \multicolumn{3}{|c|}{ SAMCEF } & \multicolumn{2}{|r|}{ ANALŸSIS } \\
\hline & 459 & 10.656 & 17.856 & & \\
\hline MESH & $12 \times 12$ & $24 \times 24$ & $20 \times 48$ & & \\
\hline \multicolumn{6}{|l|}{ Section } \\
\hline$y(\mathrm{~m}) \quad X$ & $-1.227108 \mathrm{E}-16$ & $-2.512303 \mathrm{E}-07$ & $-3.636203 \mathrm{E}-07$ & $v$ & 0 \\
\hline \multirow[t]{3}{*}{15} & $-5.744950 \mathrm{E}-03$ & $-5.520220 \mathrm{E}-03$ & $-5.454673 \mathrm{E}-03$ & $u$ & $-5.5 \mathrm{E}-03$ \\
\hline & $9.244331 \mathrm{E}-03$ & $8.804568 \mathrm{E}-03$ & $8.388786 \mathrm{E}-03$ & $w$ & $8.2 \mathrm{E}-03$ \\
\hline & 0 & $-1.718827 \mathrm{E}-07$ & $-2.431781 \mathrm{E}-07$ & & 0 \\
\hline \multirow[t]{3}{*}{11.25} & $-4.929905 \mathrm{E}-03$ & $-4.137210 \mathrm{E}-03$ & $-4.086029 \mathrm{E}-03$ & & $-4.1 \mathrm{E}-03$ \\
\hline & $5.359514 \mathrm{E}-03$ & $5.185847 \mathrm{E}-03$ & $4.917307 \mathrm{E}-03$ & & 4.6E-03 \\
\hline & 0 & $-8.053047 \mathrm{E}-08$ & $-1.285452 \mathrm{E}-07$ & & 0 \\
\hline \multirow[t]{3}{*}{7.5} & $-2.857789 \mathrm{E}-03$ & $-2.754200 \mathrm{E}-03$ & $-2.718230 \mathrm{E}-03$ & & $-2.7 \mathrm{E}-03$ \\
\hline & $2.659167 \mathrm{E}-03$ & $2.601304 \mathrm{E}-03$ & $2.463121 \mathrm{E}-03$ & & 2. $\mathrm{E}-03$ \\
\hline & 0 & $-1.974669 \mathrm{E}-08$ & $-3.952634 \mathrm{E}-08$ & & 0 \\
\hline \multirow[t]{2}{*}{3.75} & $-1.420357 \mathrm{E}-03$ & $-1.371193 \mathrm{E}-03$ & $-1.352268 \mathrm{E}-03$ & . & $-1.4 \mathrm{E}-03$ \\
\hline & $1.026303 \mathrm{E}-03$ & $1.054753 \mathrm{E}-03$ & $1.012719 \mathrm{E}-03$ & & $0.511 \mathrm{E}-03$ \\
\hline Force N & $-3.754 \mathrm{E}+06$ & $-3.806 \mathrm{E}+06$ & $-3.816 \mathrm{E}+06$ & & $-3.8197 \mathrm{E}+06$ \\
\hline
\end{tabular}

For displacements:

- The displacement results of SAMCEF are closed to analytical results for all components $x, y, z$. when Maximum numbers Degree Of Freedom (MDOF) increase

- Difference at the free end cylinder $(y=15)$ is less than $3 \%$. This difference more increases in the nieghborhood of the clamped section.

\section{For forces and moments:}

- Only normal force $N$ has result near to analytical result, the others forces and moments have results different from analytical and SAMCEF 
4.2 Cantilever cylindrical shell subjected to a concentrated force $F$

a. Consider a long cylinder $(R=1 \mathrm{~m}, \ell=15 \mathrm{~m})$ with same other characteristics in above mentioned example. Cylinder is subjected to a concentrated force $F=-1 \cdot 10^{7} N$. The-force is concentrated at one point. The mesh is: $12 \times 12$. The displacements of nodes in the line $x=0, \dot{z}=l, y=2.72727,5.454545,7.5,15(\mathrm{~m})$ are illustrated in the table 2 and figure 6

THE DISPLACEMENTS OF THE LONG CYLINDER SUBJECTED

TO A CONCENTRATED FORCE $(R=1 \mathrm{~m}, L=15 \mathrm{~m})$

\begin{tabular}{|c|c|c|c|}
\hline Section $y$ & & SAMCEF & ANALYSIS \\
\hline & $X$ & $1.724220 \mathrm{E}-13$ & $2.0886 \mathrm{E}-17$ \\
\hline \multirow{3}{*}{15} & $Y$ & $4.759142 \mathrm{E}-02$ & $3.41 \mathrm{E}-02$ \\
\hline & $Z$ & $-5.249861 \mathrm{E}-01$ & $-3.411 \mathrm{E}-01$ \\
\hline & & $5.452971 \mathrm{E}-14$ & $6.5268 \mathrm{E}-18$ \\
\hline \multirow[t]{4}{*}{7.5} & & $2.703712 \mathrm{E}-02$ & $2.56 \mathrm{E}-02$ \\
\hline & & $-1.136130 \mathrm{E}-01$ & $-1.066 \mathrm{E}-01$ \\
\hline & $N$ & $2.651 \mathrm{E}+07$ & $2.3873 \mathrm{E}+07$ \\
\hline & & $2.897783 \mathrm{E}-14$ & $3.6405 \mathrm{E}-18$ \\
\hline \multirow[t]{4}{*}{5.4545} & & $2.112250 \mathrm{E}-02$ & $2.03 \mathrm{E}-02$ \\
\hline & & $-6.381515 \mathrm{E}-02$ & $-5.95 \mathrm{E}-02$ \\
\hline & $N$ & $3.123 \mathrm{E}+07$ & $3.0384 \mathrm{E}+07$ \\
\hline & & $6.82648 \mathrm{E}-15$ & $9.7296 \mathrm{E}-19$ \\
\hline \multirow[t]{3}{*}{2.72727} & & $1.163161 \mathrm{E}-02$ & 1.13E-02 \\
\hline & & $-1.876456 \mathrm{E}-02$ & $-1.59 \mathrm{E}-02$ \\
\hline & $N$ & $-3.911 \mathrm{E}+07$ & $-3.9065 \mathrm{E}+07$ \\
\hline
\end{tabular}

b. Consider a short cylinder $(R=5 \mathrm{~m}, \ell=15 \mathrm{~m})$ with same other characteristics in above mentioned example. Cylinder is subjected to a concentrated force $F=-1 \cdot 10^{7} \mathrm{~N}$. In this case the load $F$ is considered as sum of $n(n=12)$ concentrated loads in the cross-section. The force of value $F / 12$ is acted at the each point in the end section in the direction $z$. We received a large difference of results between analysis and calculating by SAMCEF in Table 3: 


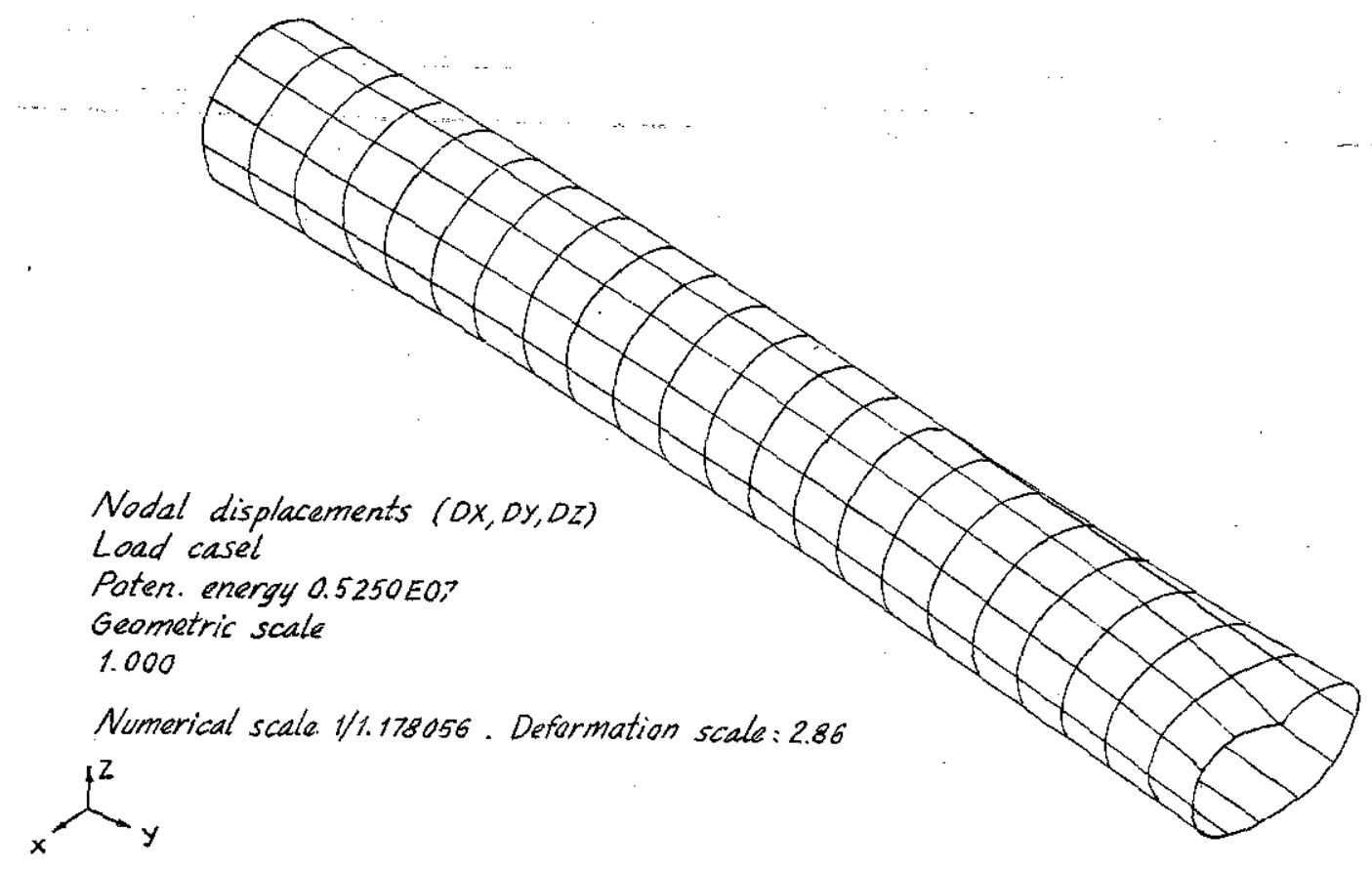

Fig. 6

THE DISPLACEMENTS OF THE SHORT CYLINDER SUBJECTED TO A CONCENTRATED FORCE

( $R=5 \mathrm{~m}, L=15 \mathrm{~m}$ for some nodes in the line $x=0, z=5, y$ - in the table)

Table 9

\begin{tabular}{|c|c|c|c|c|c|c|}
\hline \multirow{2}{*}{\multicolumn{2}{|c|}{$\begin{array}{l} \\
\text { MESH } \\
\text { Section }\end{array}$}} & \multicolumn{3}{|c|}{ SAMCEF } & \multicolumn{2}{|r|}{ ANALYSIS } \\
\hline & & $3 \times 12$ & $6 \times 12$ & $12 \times 12$ & & \\
\hline$y$ & $X$ & 7.74968E-09 & $1.38713 \mathrm{E}-10$ & $5.60046 \mathrm{E}-09$ & $v$ & $0.6707 \mathrm{E}-19$ \\
\hline \multirow[t]{3}{*}{15} & $Y$ & $1.46416 \mathrm{E}-03$ & $1.47314 \mathrm{E}-03$ & $1.47747 \mathrm{E}-03$ & $u$ & $1.4 \mathrm{E}-03$ \\
\hline & $Z$ & $-5.71599 \mathrm{E}-03$ & $-6.25301 \mathrm{E}-03$ & $-7.1449 \mathrm{E}-03$ & $w$ & $-2.7 \mathrm{E}-03$ \\
\hline & & $4.21386 \mathrm{E}-09$ & $1.08751 \mathrm{E}-10$ & 3.349685E-09 & & $1 \mathrm{E}-20$ \\
\hline \multirow[t]{2}{*}{10} & & 1.24641E-03 & $1.27032 \mathrm{E}-03$ & $1.272203 \mathrm{E}-03$ & & $1.2 \mathrm{E}-03$ \\
\hline & & $-2.97697 \mathrm{E}-03$ & $-3.2354 \mathrm{E}-03$ & $-3.164963 \mathrm{E}-03$ & & $-1.4 \mathrm{E}-03$ \\
\hline
\end{tabular}


Tables 2 and 3 show that:

- Near the end of long cylinder $(y=0)$ the difference between of SAMCEF and analytical (for displacements and force $N$ ) results is reduced.

- There is only one component $y$ of displacement (along axis y cylinder) for short cylinder has the value approximated to analysis result. The others components and forces have large difference from analysis results and the error is more $50 \%$.

- The long cylinder gives result better than a short cylinder (error $15 \%<$ $50 \%$ ). The results may be received better if $F$ is distributed at 12 points as in case for a short cylinder.

\section{Conclusions}

In this paper, two analytical results for cantilever cylindrical shell are checked by SAMCEF. In the case of moment loading, a good agreement between analytical and SAMCEF solution for displacements and normal force $N$ are obtained.

In the case of concentrated force, there are differences between these solutions, especially for short cylinder. The illustrated examples in this paper show that the long cylinder gives better agreement than a short cylinder. These differences in the both cases can be explained in the followings:

The state of stress in a shell loaded by concentrated forces will involve a moments and in plane forces in the neighborhood of the point of application of this force. The SAMCEF solution can take account all these forces and moments without any simplification while semi-moment Vlasov's theory neglected one moment and normal shear force. This theory also is limited by a second Kirchhoff assumption: The normal stresses acting on planes parallel to the middle surface may be neglected in comparison with the other stresses while on the contrary shear stresses are rather important.

The fact that the long cylinder gives a better agreement than short cylinder is expected because for a sufficiently length the loading at the free end of cylinder have less influence to stress and strain field near the middle section.

This publication is completed with financial support from the National Basis Research Program in Natural Sciences.

\section{REFERENCES}

1. Xue D. W. Some results on the theory of cylindrical shell. IASS Interna- 
tional Symposium 97 on Shell \& Spatial Structures: 10-14 November 1997, Singapore.

2. Власов В. З. Тонкостенные пространственные системы. Госстроиздат, 1958.

3. SAMCEF TX. Manuel d'utilisation. Samtech S. A., Liege, Belgium. 1994.

Received August 29, 1998

MỘT SỐ NHẬN XÉT SO SÁNH KẾT QUẢ TÍNH TOÁN VỎ TRỤ

THEO CHƯONG TRİNH SAMCEF VÀ LÝ THUYÊTT NÚA MOMENT VLASOV

Trong bài báo đã đưa ra kết quá tính toán theo phương pháp số bằng chương trình SAMCEF so sánh với kết quá giải tích trong [1] theo lý thuyết nứa moment Vlasov cho hai trường hợp vỏ trụ chịu tác dụng của moment và chịu tải tập trung. Các kết quả hội tụ tốt và chưa tốt được so sánh, nhận xét và lý giải. Những nhận xét đưa ra có thể giúp ích cho các nhà nghiên cứu, kỹ sư thiết kế trong lĩnh vực tính toán vỏ trụ. 